\title{
UM PERCURSO PELAS MARCAS INVISÍVEIS DA VIOLÊNCIA EM UMA ESCOLA PÚBLICA AMAZÔNICA ${ }^{1}$
}

\author{
Amisley Guale Araujo² \\ Lilian Coroline Urnau ${ }^{3}$
}

\section{RESUMO}

Este trabalho configura-se com um recorte de uma dissertação de mestrado, cuja análise das informações produzidas revelou duas modalidades de violência na escola: uma nomeada/sentida e outra não percebida como tal. Diante dos limites desta produção textual, abordamos mais especificamente a violência invisív el. O objetiv o deste estudo foi investigar a violência invisív el de uma unidade escolar de periferia urbana da região amazônica, a partir dos significados e sentidos atribuídos por seus integrantes, cuja localidade de seu entorno geográfico é marcada pelo estigma da violência, à luz da Psicologia Histórico-Cultural. Os procedimentos metodológicos envolveram análise documental e entrevistas individuais semiestruturadas gravadas. Participaram das entrevistas dois professores, dois alunos do ensino médio e dois funcionários de apoio. Adotamos como procedimento para análise dos dados produzidos/coletados a elaboração da seguinte categoria analítica: Marginalidades do olhar: a violência não sentida. Os resultados indicam que muitas práticas presentes no cotidiano escolar são promotoras de alienação, repercutindo em sofrimentos psicológicos/simbólicos, em perda da autonomia dos agentes e da instituição como um todo, em sentimentos de fracasso diante da precariedade de condições mínimas de ensino e aprendizagem, mas não são significadas como violências sofridas e/ou exercidas pela escola, o que se nomeou neste estudo como formas de violências invisíveis. No entanto, o sentido da violência escolar, visto como indisciplina ou crime, transfere exclusivamente aos indivíduos a responsabilidade pelo fenômeno, isentando a escola, suas ações e seus agentes de participação no que ali se produz e, fundamentalmente, da autoria dos atos de violência, a chamada violência da escola.

Palavras-chave: Violência Invisível. Significados e Sentidos. Escola de Periferia Urbana.

\footnotetext{
1 Trabalho realizado com financiamento da FAPERO e CAPES.

2 Discente do Programa de Mestrado em Psicologia da Universidade Federal de Rondônia. Email: amisley.araujo@ifro.edu.br

3 Doutora em Psicologia. Docente do Programa de Mesrado em Psicologia da Universidade Federal de Rondônia. E-mail: lilian.urnau@unir.br
} 


\title{
A JOURNEY BY MARKS INVISIBLE VIOLENCE IN A PUBLIC SCHOOL AMAZON
}

\begin{abstract}
This work is configured with a cutout of a dissertation, whose analysis of the information produced revealed two types of school violence: a named/felt and other not perceived as such. On the limits of textual production, we address more specifically the invisible violence. The aim of this study was to inv estigate the invisible violence of a school unit urban periphery of the Amazon region, from the meanings and meanings attributed by its members, whose location on your geographical area is marked by the stigma of violence, in the light of Historical-Cultural Psychology. The methodological procedures involved document analysis and recorded semistructured individual interviews. Two teachers, two high school students and two staff participated in the interviews. We adopted the procedure for data analysis produced/collected the preparation of the following analytical category: marginality look: violence not felt. The results indicate that many present practices in everyday school life are promoting alienation, reflecting in psychological/symbolic sufferings in loss of autonomy of the agents and the institution as a whole, feelings of failure on the precariousness of minimum conditions of teaching and learning, but it is not meant as violence suffered and/or carried out by the school, which is named in this study as forms of invisible violence. However, the sense of school violence, seen as indiscipline or crime, transferred exclusively to individuals responsibility for the phenomenon, exempting school, their actions and participation of agents in that there is produced and, fundamentally, the authorship of the acts of violence, call the school violence.
\end{abstract}

Keywords: Violence Invisible. Meanings and Senses. School of Urban Periphery.

\section{UN VIAJE POR MARCAS VIOLENCIA INVISIBLE EN UNA ESCUELA PÚBLICA}

\section{AMAZON}

\section{RESUMEN}

Este trabajo está configurado con un recorte de una tesis, cuyo análisis de la información producida puesto de manifiesto dos tipos de violencia en la escuela: una llamada/fieltro y otra que no son percibidos como tales. En los límites de la producción textual, nos dirigimos más específicamente la violencia invisible. El objetiv o de este estudio fue investigar la violencia invisible de una periferia urbana unidad escolar de la región amazónica, a partir de los significados y significados atribuidos por sus miembros, cuya ubicación en su zona geográfica está marcada por el estigma de la violência, a la luz de la Psicología Histórico-Cultural. Los procedimientos metodológicos de análisis de documentos y entrevistas individuales semiestructuradas grabadas. Participado en las entrevistas dos profesores, dos estudiantes de la escuela secundaria y dos funcionarios. Hemos adoptado el procedimiento para el análisis de los datos producidos/recogimos la preparación de la categoría analítica siguiente: mirada marginalidad: la violencia no sentía. Los resultados indican que muchas de las prácticas actuales en la vida cotidiana de la escuela son la promoción de la alienación, lo que refleja en los sufrimientos psicológicos/simbólicos en la pérdida de la autonomía de los agentes y de la 
institución en su conjunto, sentimientos de fracaso en la precariedad de las condiciones mínimas de enseñanza y aprendizaje, pero no se entiende como violencia sufrida y/o lleva a cabo por la escuela, que se nombra en este estudio como formas de violencia invisible. Sin embargo, el sentido de la violencia escolar, visto como la indisciplina o la delincuencia, transferido exclusivamente a los individuos responsabilidad por el fenómeno, la escuela eximir, sus acciones y la participación de los agentes en que no se produce $y$, fundamentalmente, los autores de actos de violencia, llamada la violencia de la escuela.

Palabras clave: Violencia Invisible. Significados y Sentidos. Escuela de Periferia Urbana.

\section{INTRODUÇÃO}

Este trabalho configura-se com um recorte de uma dissertação de mestrado em Psicologia intitulada "Significados e sentidos da violência escolar para integrantes de uma unidade de ensino na Amazônia Ocidental", cujo objetivo foi analisar os significados e sentidos produzidos por diferentes integrantes da comunidade escolar sobre a violência numa escola de periferia urbana na Amazônia. A análise das informações produzidas ao longo do trabalho de campo levou-nos à constatação de duas modalidades de violência na escola: uma nomeada, sentida, e outra não percebida como tal. Diante dos limites desta produção textual, aqui abordaremos mais especificamente a segunda modalidade, a violência invisível.

Partimos do entendimento de que as escolas configuram-se como lócus que, por um lado, constituem relações sociais específicas e, por outro, não estão apartadas das relações sociais mais amplas da sociedade, tal como aponta Saviani (2008), não sendo nem redentora da humanidade, nem mera reprodutora da sociedade. Neste sentido, a violência vivida no cont exto escolar precisa ser analisada sob ambas as dimensões.

A violência é hoje um dos temas sociais mais discutidos pelos diferentes setores da sociedade. Embora sua abordagem não seja nova, Sposito (2001) afirma que sua ampliação como objeto de estudo das ciências somente ocorreu a partir dos primeiros anos da década de 1980, com diferentes olhares e métodos utilizados. Segundo esta autora "[...] as equipes de 
pesquisadores demoram a assimilar no conjunto de seus interesses o tema das relações entre violência e escola" (p. 89).

Mais recentemente, de acordo com um levantamento bibliográfico, realizado na base de dados do portal da Coordenação de Aperfeiçoamento de Pessoal de Nível Superior (CAPES), com as palavraschave violência escolar e violência no contexto escolar, encontramos 2.205 trabalhos, produzidos na última década, sendo que apenas 161 produções são de nível Stricto Sensu, das quais 29 foram em programas de pósgraduação em psicologia. Dentre os estudos no campo da psicologia poucas são as publicações que buscam compreender este fenômeno a partir do olhar de seus atores. No entanto, nenhum dos trabalhos disponibilizados no Portal CAPES na área tratou de maneira específica os significados e sentidos da violência escolar na perspectiva histórico-cultural.

Visto que ainda são poucos os estudos que versam sobre instituições escolares da região amazônica, destacamos a relevância desta pesquisa, que ainda se propôs a analisar as narrativas e experiências de diferentes sujeitos que vivenciam o cotidiano escolar sobre a violência.

É necessário ressaltar que este estudo partiu do pressuposto de que os significados e sentidos não constituem exclusivamente processos subjetivos e singulares, mas são necessariamente construções pautadas na realidade objetiva, necessariamente mediada pelas relações sociais, conforme os pressupostos da Psicologia Histórico-Cultural que apresentaremos em seção subsequente.

Com isso, objetivou-se nesse trabalho investigar a violência invisível de uma unidade escolar de periferia urbana da região amazônica, a partir dos significados e sentidos atribuídos por seus integrantes, cuja localidade de seu entorno geográfico é marcada pelo estigma da violência. 


\section{A COMPREENSÃO DA VIOLÊNCIA NA SOCIEDADE DE CLASSE}

Ao olharmos para a constituição da sociedade moderna percebemos que, subjacente ao seu desenvolvimento, encontra-se uma visão historicamente construída de dominação das classes mais vulneráveis. Por meio dos mais diferentes mecanismos de controle institucionais, buscou-se disseminar as ideias e valores da classe dominante, ligada aos interesses políticos e econômicos do sistema vigente, os quais não se traduziram em melhorias para população mais pobre.

Para Duarte (2013), este cenário corresponde à alienação das relações sociais capitalistas, pois, segundo este autor, estas relações "[...] impedem, ou ao menos limitam, a concretização das máximas possibilidades de vida humana na vida de cada indivíduo" (p. 59). Dessa maneira, o ser humano passa a ser dominado pelo produto da sua própria atividade social, como se este existisse independentemente dele, estando dotado de poderes próprios. Assim, ao invés do indivíduo dominá-lo subjuga-se a ele.

Portanto, quanto maior a desigualdade numa sociedade, maiores são as contradições e os conflitos entre as classes dominante e proletária, aumentando ainda mais a distância no relacionamento entre as periferias e centros urbanos. Conforme Corrêa (2000) as áreas periféricas pobres são as que mais sofrem as mazelas e carências, impostas por uma estrutura desigual e contraditória, influenciada por interesses econômicos que visam sua exploração e dominação.

Segundo Duarte (2013), a sociedade capitalista é marcada pela constante luta de classes, fazendo com que a grande maioria das pessoas desenvolva sua humanidade em condições muito abaixo das máximas possibilidades de desenvolvimento do gênero humano. Embora esta sociedade tenha produzido níveis de desenvolvimento humano livre e universal sem precedentes na história da humanidade, sua concretização tem sido limitada por esta mesma sociedade. Neste sentido, Duarte (2013, p.11) afirma que "nunca o ser humano conheceu tão profundamente a 
natureza e nunca a utilizou tão universalmente, mas também nunca esteve tão próximo da destruição total da natureza e de si próprio".

Este caráter contraditório do processo de objetivação e apropriação tem desempenhado também uma função contraditória na formação do ser humano, pois tanto a objetivação quanto a apropriação podem desempenhar uma função humanizadora ou alienadora na vida do indivíduo, que não dependerá de suas características hereditárias, mas "[...] do conjunto complexo e dinâmico das relações sociais nas quais o indivíduo está inserido [...]" (DUARTE, 2013, p. 12).

Sendo assim, percebe-se que na sociedade dividida por classes o desenvolvimento humano ocorre dentro de limites restritos de sua capacidade livre e universal, não conseguindo desenvolver sua individualidade acima das suas necessidades naturais. Dessa forma, para que o ser humano possa avançar, no desenvolvimento da individualidade, é necessário que as formas de alienação da sociedade capitalista sejam superadas.

Segundo Corrêa (2000), para se discutir os fenômenos existentes nas periferias urbanas, diferentes fatores, tais como sociais, econômicos e políticos devem ser levados em consideração, evitando o erro de tratar seus problemas como restritos a essas comunidades, sendo exclusivos delas e não como problemas sociais que se manifestam nas relações sociais alienantes de uma sociedade classista. Contudo, não podemos ignorar o fato de que são em comunidades vulneráveis que os dramas sociais afloram, manifestando com maior intensidade os problemas que afligem mais duramente a população pobre e socialmente vista como periférica.

Um desses problemas sociais, muito debatido na atualidade, é o fenômeno da violência. Porém, é muito comum esbarrar em explicações simplistas e deterministas, principalmente aquelas que consideram a periferia como sinônimo de violência, pela associação direta com pobreza. Essas explicações não levam em consideração diversos fatores que cecam esse problema social e só reforçam os estigmas que marcam seu cotidiano, que 
impulsiona e alimenta uma leitura distorcida da realidade dessas comunidades.

Contudo, ignora-se o fato de que a violência não se manifesta pela pobreza, mas pela intensificação da desigualdade social, conforme afirma Sposito (2001). Para Ansara e Costa (2009), a relação entre pobreza e violência faz parte da ideologia dos poderes instituídos, que transfere para a população pobre a responsabilidade pela violência, deixando de reconhecer a exclusão dessa população dos direitos sociais mais elementares. Nesse sentido, Silva (2006) afirma que, compreender o fenômeno da violência sem compreender a forma como a sociedade está organizada, bem como seus interesses, tem levado a interpretações superficiais focalizadas apenas na figura do indivíduo, desprezando toda sua complexidade.

Ao consideramos as diferentes abordagens sobre as manifestações da violência, um aspecto comum se destaca em todas elas, que consiste no fator determinista, que está fortemente influenciado pela corrente filosófica do positivismo, defensora da ideia de um conhecimento científico absoluto, ancorado em métodos de pesquisas aceitos como objetivos e neutros e, por isso, inquestionáveis.

Para Collares e Moysés (1996), trata-se de um processo de biologização, que visa transformar os fenômenos sociais em biológicos. Para essas autoras, o propósito de biologizar as questões sociais, consiste em atribuir a culpa aos indivíduos, isentando de qualquer responsabilidade 0 sistema social, o que, para elas, trata-se de uma concepção ideológica, que vai ao encontro dos interesses de uma sociedade burguesa que objetiva a perpetuação de seus privilégios e, por isso, aceita e propaga facilmente esse cientificismo biologizante.

Além dessas teorias, que dominaram ao longo dos anos as discussões sobre o tema, Silva (2006) acrescenta outra abordagem sobre o fenômeno da violência, que, baseada nos pressupostos da Psicologia Histórico-Cultural, tem levado os estudiosos a ampliar a compreensão sobre o problema. Nessa 
perspectiva, busca-se olhar para esse fenômeno social na sua complexidade, considerando suas múltiplas dimensões e sua constituição histórica.

Nesse sentido, a autora afirma ser esta uma das grandes contribuições trazidas por essa corrente teórica para as pesquisas sobre violência, ou seja, a compreensão de que esse fenômeno não é meramente instintivo. Tampouco é uma simples consequência de fatores ambientais e, muito menos, uma combinação de ambos. Segundo Silva (2006), precisamos compreendê-lo como condição sócio-histórica e produto das relações humanas, e, portanto, pode ser transformado por meio de processos educativos que construam formas distintas de mediação que prescindam do uso da violência. Conforme essa mesma perspectiva, Ansara e Costa (2009), afirmam que a existência do diálogo e da participação faz com que as práticas violentas sejam atenuadas ou dissolvidas.

A partir dessa perspectiva, Silva (2006) afirma que a própria forma como a sociedade está organizada, por meio da exploração de classes menos favorecidas, evidencia um tipo de violência, compreendida por ela como estrutural. Para ela, "[...] no capitalismo atual, a violência se mostra tanto nas formas diretas e organizadas de uma violência real ou possível, como na violência vinculada ao caráter alienante e explorador das relações humanas" (p. 27). Neste sentido, conforme a mesma autora, uma sociedade dividida em classes antagônicas tende a recorrer à violência, sempre que tiver interesses vitais ameaçados.

A compreensão restrita do conceito de violência impede-nos que percebamos as práticas sutis, realizadas no cotidiano social e, muitas vezes, aceitas como normais, mas que causam a destruição da humanidade do outro. O conceito ampliado do termo visa alcançar essas formas de violência que escapam do sistema jurídico, por não serem contempladas pelas leis penais (ABRAMOVAY et al, 2009).

Nessa acepção, para Zaluar e Leal (2001), trata-se de negar a exist ência do outro, tirando dele sua condição essencialmente humana, que 
é a sua capacidade de se relacionar por meio da linguagem. Nesse caso, a violência é caracterizada pelo não reconhecimento do outro, ou seja, o não reconhecimento da vítima como ser humano, que passa a não existir na relação. O opressor, portanto, nega-lhe o diálogo. Assim, a vítima passa a ser percebida apenas como coisa, algo inferior, não sendo digna de atenção.

De acordo com Abramovay et al (2009), a violência como negação da dignidade humana evidencia sua íntima relação com a desigualdade, em que alguém (pessoa ou instituição) exerce um domínio sobre o outro, através do uso injusto do poder ou da força, mesmo que a violência seja aceita e justificada socialmente. Para essas autoras, o entendimento mais amplo do conceito de violência faz com que as próprias estruturas sociais sejam consideradas violentas.

\section{VIOLÊNCIA NO CONTEXTO ESCOLAR}

Nessa direção, Aquino (1996, p. 41) discorrendo especificamente sobre a violência no contexto escolar afirma que "[...] não é lícito supor que o que ocorre em seu interior não tenha articulação aos movimentos exteriores a ela. Claro está também que as relações escolares não implicam um espelhamento imediato daquelas extras-escolares". Temos assim, de um lado uma força exercida pelos poderes constituídos que por meio de instrumentos de dominação, como a imposição de normas e a repressão, visam o controle dos sujeitos escolares, exigindo deles a submissão e a passividade. De outro lado existe uma força contrária a essa dominação, que busca a diferenciação dos grupos em face da uniformidade imposta. Segundo Guimarães (1996), forma-se uma tensão entre essas duas forças antagônicas, denominada por ele do "dever ser" e do "querer viver" respectivamente, e quando a primeira se sobrepõe a segunda, o que temos é um aumento da violência cotidiana.

É preciso compreender que a escola é formada por uma complexa rede de relações, que no seu dia-a-dia gera tensões pela existência de 
conflitos entre as diferentes forças que agem sobre ela. Segundo D'AureaTardeli (2009, p. 106), o conflito "[...] é inevitável à existência humana, além de ser necessário", pois faz parte das práticas sociais e educativas libertadoras. Para Charlot (2002) não devemos esperar que o conflito assim como a agressividade desapareçam, mas procurar controlá-los pelo uso da palavra e não pela violência. Nas palavras do autor "[...] o que está em jogo é a capacidade de a escola e seus agentes suportarem e gerenciarem situações conflituosas, sem esmagar os alunos sob o peso da violência institucional e simbólica" (p. 436). Em meio a esse tensionamento, cabe à escola negociar esses conflitos.

Outra dimensão fundamental à compreensão da violência escolar é a desvalorização do trabalho do professor. Conforme Facci (2004) a sociedade capitalista não tem interesse em que os professores promovam a socialização do conhecimento histórico-científico que leva os alunos ao saber crítico para a "[...] consciência de sua condição de exclusão dessa sociedade e dos seus bens culturais" (p. 33). Mas na realidade prevalecem os preceitos neoliberais, cujo objetivo maior é a empregabilidade, valorizando mais a competência e aquisição de habilidades, do que o conhecimento que promova "[...] mudanças na consciência dos alunos que passam pelo processo de escolarização" (p. 34). Para esta autora o que ocorre é uma desvalorização da escola e a banalização do conhecimento.

Com isso, Rego (1996), fundamentada na perspectiva da Psicologia Histórico-Cultural de Vigotski, afirma que os atos de violência ocorridos na escola devam ser vistos não somente como causas de fatores externos, mas também como sinais de práticas pedagógicas equivocadas ocorridas na escola, pois a escola produz também sua própria violência (AQUINO, 1996; GUIMARÃES, 1996).

Diante das distintas formas de manifestação da violência escolar, Charlot (2002) propõe a diferenciação de três tipos. A primeira é a violência na escola, que corresponde àquela que ocorre dentro do espaço escolar, mas que poderia ocorrer em qualquer outro lugar; a segunda é a violência à 
escola, caracterizada por aquela dirigida contra os professores, os funcionários e a própria estrutura física, como depredações e furtos e por fim, a violência da escola, como sendo aquela dirigida contra os alunos e realizada diretamente pela escola.

Ao fazer essa distinção entre as violências no contexto escolar, Charlot (2002) afirma a necessidade de uma análise conjunta da violência contra a escola e da escola. Assim, podemos entender que o estudo deste fenômeno pode ser tanto exógeno, correspondendo à violência na escola, quanto endógenos, ou seja, a violência contra e da escola. Corroborando com esta assertiva, estão Abramovay e Ruas (2002), quando afirmam que a compreensão do fenômeno da violência escolar passa necessariamente pela consideração de fatores externos e internos à instituição, uma vez que a violência não é um fenômeno unicausal, mas são várias as causas que podem influenciar sua ocorrência, fazendo com que também a violência não seja única, mas existam múltiplas violências. Assertiva que vai ao encontro das considerações de Rego (1996), nas quais a escola deve buscar também nas suas práticas os motivos para violência, além dos aspectos exteriores.

\section{METODOLOGIA}

Para atingir os objetivos que propomos neste trabalho, optamos pela abordagem metodológica qualitativa. Visto que, conforme Bogdan e Biklen (1994), o estudo qualitativo se caracteriza pelo contato direto do investigador com o local da pesquisa, devendo este levar em consideração as interações sociais e o contexto em que as informações são produzidas, para melhor compreendê-las.

\section{Atividade de significação e produção de sentidos}

O que é transmitido para o sujeito não é a imagem real do objeto, mas seu significado social e do sentido pessoal relacionados à uma comunidade, de uma determinada cultura, numa dada época histórica. Desta forma, 
podemos dizer que o desenvolvimento psicológico se relaciona diretamente com a estrutura social na qual o indivíduo está inserido. $O$ uso dos signos como produto cultural, ou seja, fruto da elaboração social visa à comunicação de significados aos demais componentes de um grupo social e tem a função de compreender as mudanças físicas e psíquicas no ser humano.

Nesse caminho, Vigotski (2009) apresenta a linguagem como principal mediador na construção e no desenvolvimento das funções psicológicas superiores, uma vez que tem o papel de representar a realidade por meio do pensamento, dando a esta realidade um sentido subjetivo. Com base nos estudos de Frederic Pauhlan, que trouxe importantes contribuições no estudo da linguagem ao introduzir a diferença entre o significado e o sentido da palavra, Vigotski (2009, p. 465) conceitua este como "a soma de todos os fatos psicológicos que ela desperta em nossa consciência". Esta compreensão faz com que a palavra adquira sentido no contexto e se modifique em contextos diferentes, o que não ocorre com o significado, sendo mais estável e preciso. Ainda compartilhando das ideias de Pauhlan, para Vigotski (2009, p.465), "[...] o sentido tem várias zonas de estabilidade diferentes. O significado é somente uma dessas zonas do sentido".

Desta forma, conforme Aguiar et al (2015), para Vigotski a significação da palavra possui dois componentes distintos na análise da linguagem: o significado propriamente dito e o sentido. O primeiro faz parte do coletivo, sendo elaborado historicamente e compartilhado por todos aqueles que integram um determinado grupo social, caracterizado como um sistema de significação encontrado já pronto para o indivíduo ao nascer. O segundo, que é o sentido, está voltado para a subjetividade, caracterizado como particular, que vai depender das experiências de cada pessoa, da realidade em que vive e da forma com que ela se apropria dessa realidade.

Ao nos debruçarmos sobre os conceitos de significado e sentido relacionados ao processo de significação atribuído por Vigotski, com base em seus estudos sobre o desenvolvimento do pensamento e palavra, 
verificamos seu impacto significativo nas investigações psicológicas. Concordando com Barros et al (2009), que ao pesquisarem sobre as implicações do conceito de sentido para a investigação psicológica afirmam que tais conceitos "[...] contribuíram, sobremaneira, para 0 alargamento das possibilidades de estudo das interações sociais e dos processos de significação nelas inscritos" (p. 180).

Para estes autores, uma das contribuições para os estudos dos significados e sentidos na psicologia está no caráter dinâmico dos sentidos, possibilitando que o pesquisador avance na compreensão do fenômeno investigado além do seu significado propriamente dito. O que leva a outra abertura nesse tipo de investigação, que consiste nas diferentes produções de sentidos para o mesmo fenômeno, visto que por meio das relações sociais ele é formado. Consequentemente, compreende-se que essa produção de sentidos ocorre não como um simples reflexo das relações sociais, mas da dialética entre o coletivo e o individual.

\section{Procedimentos de produção e análise dos dados}

Com o objetivo de fundamentar a análise dos significados e sentidos atribuídos pelos atores escolares sobre a violência numa escola de periferia urbana e para o bom andamento do estudo, foram utilizados os seguintes procedimentos para produção dos dados: análise documental e entrevistas individuais semiestruturadas gravadas em áudio. Também adotamos um registro de campo, no qual foram relatados os procedimentos $e$ acontecimentos vivenciados no percurso da pesquisa, bem como os aspectos considerados importantes durante a construção dos dados, tais como: questões levantadas pelo trabalho de campo ou estudos teóricos, proposição da pesquisa, reações dos sujeitos nas entrevistas.

Os procedimentos de análise foram sendo construídos à medida que os dados emergiam do campo de pesquisa, sendo produzidos ou coletados a partir dos instrumentos empregados neste estudo, relacionando-os 
dialeticamente com o material teórico levantado em nossa pesquisa bibliográfica.

A exploração dos dados construídos deu-se pelo recorte em categorias de análise, que consiste em agrupar elementos, pensamentos ou manifestação a um conceito capaz de incorporar estes aspectos, e sua utilização tem sido muito comum nas pesquisas qualitativas, por facilitar sua análise (GOMES, 2002). Para este estudo, adotamos como procedimento metodológico para análise dos dados produzidos/coletados a elaboração da seguinte categoria analítica: Visibilidades e invisibilidades da violência escolar.

\section{Participantes da pesquisa}

Foram participantes desta pesquisa dois professores, dois alunos do ensino médio e dois funcionários (um porteiro e o outro inspetor de alunos) de uma escola pública de ensino fundamental e médio, localizada numa área de periferia no município Amazônico. Esta pesquisa se limitou aos atores escolares que interagem, vivenciam e atuam cotidianamente no espaço escolar e que, portanto, detém prismas de olhar privilegiados ao tema deste estudo.

Todos colaboradores desta pesquisa tiveram seus nomes verdadeiros substituídos por siglas conforme o segmento de cada um dos atores escolares, seguidos do número 1 ou 2, com o propósito de manter suas identidades preservadas. Os professores foram identificados com a letra $\mathrm{P}$, os alunos com a letra A e para os outros servidores utilizamos a letra S como identificação.

\section{O Recorte da Pesquisa}

A Escola pesquisada está localizada em um bairro, cuja população possui uma renda per capita considerada baixa, conforme o levantamento feito pela própria escola. Atualmente ela atende em três turnos (matutino, vespertino e noturno), ofertando à comunidade o ensino fundamental e 
médio. A partir do ano de 2000 a escola passou a trabalhar também com a educação de jovens e adultos (EJA). Em 2009, com a implantação do Projeto Mais Educação, a escola passou a ser de tempo integral para o ensino fundamental, mas somente em meados dos anos 2010, começou a atender efetivamente em tempo integral, sem, entretanto, deter condições físicas, materiais e estruturais, para atender o contingente dobrado de alunos.

\section{Marginalidades do olhar: a violência não sentida}

A pesquisa que originou esse estudo apontou para dimensões mais evidentes aos olhares dos participantes da pesquisa e as proximidades e os distanciamentos com a vivência concreta e cotidiana do fenômeno. Ainda, indicou dimensões menos, ou não evidentes, aos entrevistados. Para percorrer essas marcas visíveis e invisíveis da violência, utilizamos como guia da discussão a distinção, elaborada por Charlot (2002), entre as formas de violência: na, da e contra a escola. Embora a análise inicialmente esteja alicerçada nessa diferenciação, esse fenômeno não será considerado como partes isoladas que se somam na escola. Pelo contrário, com base nos pressupostos da Psicologia Histórico-Cultural, por meio do sentido da violência atribuído pelos atores escolares é possível compreender esse fenômeno na sua totalidade, nas unidades que dialeticamente se interconectam, enquanto produtos de relações sociais, cultural e historicamente estabelecidas pela humanidade.

Nesse contexto, percebemos nos relatos dos participantes que a maioria se refere à violência ocorrida na escola manifestada na forma de brigas físicas ou verbais. Para Charlot (2002) essa violência corresponde à violência ocorrida na escola, mas que poderia ocorrer em qualquer outro lugar. Sua classificação considera apenas o local em que ela ocorre. Os sentidos associados às motivações dessas brigas foram distintos entre os entrevistados, contudo, percebemos o predomínio do tráfico de drogas e relações afetivas/amorosas. 
Além da violência na escola, Charlot (2002) relata também a violência contra a escola, que consiste em danos ao patrimônio escolar e às pessoas que a representam. Nesse sentido, destacamos o predomínio, nos relatos dos participantes, de furtos e roubos contra a escola e seus integrantes, sendo tais casos, relacionados muitas vezes ao consumo de drogas.

Além da violência percebida pelos participantes e bastante divulgada pelos órgãos da mídia e da segurança pública, ficando mais evidente aquela dirigida a materialidade do corpo causando dor física no outro, fundamentalmente atribuída aos alunos. Verificou-se ao longo das entrevistas dados que evidenciam outras violências que não apareceram diretamente nas falas dos entrevistados e muito menos são divulgadas pela imprensa e pelas autoridades constituídas. Por ser uma violência que não está inscrita no código penal e, por sua definição fugir do sentido lexical, torna-se invisivel e de difícil percepção aos olhares presos as compreensões restritas e individualizadas desse fenômeno. É dessa violência que falaremos agora.

Para tanto, categorizamos três formas principais de violência não sentida pelos participantes da pesquisa, a saber: preconceito e discriminação dirigidos à escola; responsabilização pelos processos de aprendizagem individual e polarizada; e verticalização e precariedade nas condições de trabalho.

\section{Preconceito e discriminação dirigidos à escola}

Dentre as violências observadas, chamamos a atenção para a desigualdade social e o preconceito, que fazem dos moradores de bairros pobres as principais vítimas de um sistema econômico que as impede de acessar os bens de produção social. Com isso, através da propagação do significado restrito do conceito de violência, como sendo a falta de normas e/ou descumprimento de leis, produzidos historicamente por uma minoria e compartilhados no meio social no qual ela está inserida, procura-se manter o stat us quo desse sistema. 
Para ampliarmos essa análise, iniciamos nossa reflexão com os sentimentos de nossos participantes com relação a trabalhar ou estudar na unidade de ensino. Ao analisarmos as respostas, percebeu-se que todos foram unânimes ao relatarem que se sentem bem trabalhando ou estudando na referida instituição. Percebeu-se também, de forma geral, a existência de um bom convívio entre os integrantes no interior da escola, o que contribui para um bom desenvolvimento das atividades.

Esses relatos demonstram que o sentimento vivido nessa escola não é de medo, terror ou desânimo, o que contraria outros resultados de estudos realizados em escolas marcadas pela violência e localizadas em bairros pobres. Na pesquisa de Souza (2011), por exemplo, os participantes afirmaram ter medo de trabalhar na escola por ser um lugar violento. Alguns ainda demonstraram um sentimento de desmotivação por trabalharem na referida escola. Como consequência, muitos professores procuravam a transferência para outras escolas para se sentirem mais seguros. Esse ato gera uma rotatividade que, segundo Souza (2007), acaba repercutindo negativamente na qualidade do ensino.

Embora os integrantes do cotidiano da escola investigada experimentem um sentimento que lhe é favorável, prevalece por parte de alguns segmentos da sociedade o sentimento de medo e rejeição, alimentado por um forte discurso que criminaliza instituições pertencentes a bairros pobres, marcados pela violência. Fato que corrobora a ideologia dominante, que estabelece o lugar social que cada um deve ocupar dentro de uma sociedade dividida por classes. Essa realidade foi percebida em vários momentos desta pesquisa. Um deles está no diálogo com uma das servidoras ${ }^{4}$ da escola:

Esta escola é uma escola boa, ao contrário do que muitas pessoas pensam, por ser uma escola localizada num bairro considerado violento. Eu me sinto bem trabalhando aqui,

\footnotetext{
4 Relato não gravado, registrado no diário de campo e obtido por meio de uma conversa informal tida com uma servidora no momento em que fomos apresentados pela vicediretora ao corpo técnico da escola. Neste caso, apresentamos o Termo de Consentimento Livre e Esclarecido (Apêndice B).
} 
apesar do meu marido não gostar, ele teme por eu trabalhar aqui e tem tentado conseguir minha transferência para uma escola mais central. Eu digo para ele que aqui é bom, mas ele não acredita.

Por se tratar de uma escola associada à violência atribuída ao bairro, - que nela prevalece não são os atos de violência extrema, mas o preconceito por parte daqueles que residem fora de sua comunidade. A força desse discurso também reverbera entre aqueles que geralmente são alvos desse preconceito, como podemos const atar no relato do participante A 1: "Acontecia muita violência aqui, era muito mal falado o bairro, né? Inclusive quando eu cheguei aqui, também incluía a escola também do bairro né? As [outras] escolas falavam que era ruim".

Esse fato nos remete a uma situação vivenciada, na qual alunos de uma escola pública de periferia também eram discriminados e chamados de bandidos pelo simples fato de residirem no bairro, cuja fama era de ser violento. Com isso queremos chamar a atenção para a existência de um preconceito associado à escola investigada que, consequentemente, atinge os sujeitos que nela trabalham e estudam. Isso configura também uma forma de violência contra a instituição, uma vez que esses olhares possivelmente guiam as relações e ações entre os partícipes da unidade de ensino e as pessoas alheias a seu cotidiano, possivelmente configurando campos de resistência e hostilidade.

\section{Responsabilização pelos processos de aprendizagem individual e polarizada}

Outra questão pertinente, presente nas entrelinhas das falas dos participantes em relação aos sentimentos para com escola, é uma forma sutil de violência praticada por ela, em que o professor é tanto vítima quanto autor, como ficará evidente nesta e na próxima categoria de análise. Por constituir uma violência que se estrutura nas relações hierárquicas do sistema educacional, o aluno torna-se a principal vítima. Conforme Charlot (2002), ela é causada pela própria instituição e é considerada como a violência da escola. É um fenômeno regido pela violência simbólica e camuflado pelas 
políticas educacionais e instrumentos pedagógicos. Um exemplo disso é o emprego de um sistema de avaliação que impõe ao aluno a responsabilidade pelo seu sucesso ou fracasso, conforme expôs o participante P1: "O aluno tem que passar, por condições de passar". Esse discurso é também assumido pelos alunos, que se responsabilizam exclusivamente pelas falhas e notas baixas, o que foi evidenciado na fala de A2: "[...] Mas se a gente não tira nota boa ou coisa assim, é falha nossa também. A gente que não estuda".

Em outro momento, ao relatar uma briga entre alunas, P1 destaca: "[...] até me decepcionei com elas porque as três eram boas de notas, alunas normais, não me davam problema". A avaliação aqui se revela excludente, pois julga a capacidade do aluno a partir de um critério exclusivamente quantitativo, que serve de parâmetro também para seus comportamentos, pois o bom aluno não é aquele que apenas tira boas notas, mas que também tem comportamento exemplar. Nota-se, que o sucesso pedagógico está voltado para um aluno idealizado no imaginário do professor. Para Guimarães (1996), trata-se de uma escola que é pensada para um tipo de aluno dócil e obediente, que não causa "problemas" e que é ocupada por outro diferente do padrão pedagógico idealizado.

Contribundo com esta análise, destacamos as seguintes falas:

[...] sou um aluno que gosta muito de se dedicar, os professores também se empenham a ajudar os alunos a trabalhar sobre os comportamentos. (A1)

[...] Mas se a gente não tira nota boa ou coisa assim, é falha nossa também. A gente que não estuda. (A2)

É possível percebermos nas falas tanto de Al quanto de A2, O funcionamento do mecanismo de homogeneização da escola, que impõe a seus alunos uma atitude de submissão por meio das práticas pedagógicas disciplinadoras, em detrimento do papel de mediar o conhecimento sistematizado, contribuindo muito mais para desmotivar e excluir o aluno do aparelho escolar, do que para seu sucesso acadêmico. Por conseguinte, o 
aluno incorpora sem qualquer questionamento os discursos da ascensão social e da meritocracia propagados por um sistema educacional que é excludente, produzindo alunos normatizados e idealizados segundo os interesses da classe dominante. Tal ideologia também pode ser considerada uma forma de violência.

O sentido de escola atribuído por ambos os alunos participantes do estudo vai ao encontro dessa ideologia, o que pode justificar a percepção dos mesmos em relação à violência no contexto escolar, a qual em alguns momentos tem sua existência negada e, em outros, tem uma ocorrência atribuída aos próprios alunos. Diante dessa análise, cabe questionar qual seria a percepção da violência por parte do aluno que não confere ao estudo um sentido pessoal positivo ou necessário? Para aqueles que não correspondam aos padrões ideias? Nisso também residem elementos que compõem a complexa rede de causas e efeitos da violência escolar, diante da excessiva preocupação com a disciplina e os bons comportamentos, em detrimento dos processos de ensino e aprendizagem.

\section{Verticalização e precariedade nas condições de trabalho}

Consideramos também importante destacar outra forma de violência não sentida pelos participantes, identificada a partir de uma fala do professor P1: "[...] Alguns professores que, por ganharem pouco, às vezes, eles julgam ganhar pouco, querem fazer as coisas de qualquer maneira".

Diante do exposto, é possível identificarmos o processo de alienação presente nas relações sociais capitalistas. Ao relatar que alguns professores, devido ao baixo salário, "fazem as coisas de qualquer jeito", reproduz o discurso dos poderes constituídos que responsabilizam exclusivamente o professor pelo fracasso escolar dos alunos, ignorando muitas vezes a situação precária das condições de trabalho a que esse profissional é submetido. Logo, seria a falta de comprometimento do professor com sua função de ensinar ou seriam as precárias condições de trabalho enfrentadas cotidianamente por esse profissional a causa para sua falta de entusiasmo? 
Para Souza (2007), o baixo salário pode produzir a insatisfação do professor que em longo prazo acaba refletindo na sua práxis, por produzir nele um sentimento de desvalia em relação a sua atividade produtiva. Segundo Duarte (2013), com base nos estudos de Leontiev, o homem se humaniza através da sua atividade produtiva, que é o seu trabalho, considerado como uma fonte vital do homem. Quando ele vende sua força de trabalho no processo de produção capitalista, ocorre uma ruptura entre o sentido e o significado da atividade produtiva, pois o sentido da sua atividade não é mais o produto dela e sim o salário que ele vai receber como valor de troca da força de trabalho. Com isso, o trabalho torna-se alheio à personalidade do trabalhador, ou seja, o homem é alienado do seu trabalho que passa a ser externo e estranho a sua individualidade e necessidades. Conforme este autor, "[...] sua atividade é apenas um meio para sua sobrevivência, e não uma forma de o indivíduo se realizar e se desenvolver como ser humano [...]" (p. 71). Trata-se, portanto, de uma violência à dignidade do professor, legitimada por um sistema educacional conivente com o interesse econômico capitalista.

Nesse sentido, compartilhamos da afirmação de Souza (2007, p. 257), "[...] as condições de trabalho são os fatores de maior peso na produção de aulas de baixa qualidade". Portanto, tanto o baixo salário é uma violência, quanto o ensino de baixa qualidade também o é. Cabe questionar nesses casos quem são as vítimas e quem são os culpados.

Outra situação que consideramos ao mesmo tempo como uma manifestação de violência da e contra a escola, mas não é sentida como tal pelos entrevistados, está na forma como é implantado o Programa de Educação Tempo Integral do Governo do Estado. A Educação em Tempo Integral consiste num programa articulado com o Governo Federal, que amplia a jornada escolar ofertando atividades diversificadas no contra turno escolar, com o objetivo de contribuir para a formação integral de crianças, adolescentes e jovens. 
A elaboração desse Programa A elaboração desse Programa representa uma proposta educativa que visa proteger as crianças, adolescentes e jovens, como cidadãos possuidores de direitos, em todas as suas dimensões, considerando suas necesidades, posibilidades e intereses. Na Portaria N 17, de 24 de abril de 2007, o Ministério da Educação establece no artigo $2^{\circ}$ e inciso IV, como uma das finaidades do programa:

Prevenir e combater o trabalho infantil, a exploração sexual e outras formas de violência contra crianças, adolescentes e jovens, mediante sua maior integração comunitária, ampliando sua participação na vida escolar e social e a promoção do acesso aos serviços sócio-assistenciais do Sistema Único de Assistência Social - SUAS (s/n).

Portanto, um dos objetivos do programa é contribuir para a diminuição da violência contra crianças e adolescentes, aumentando o tempo de permanência dos mesmos na escola e ofertando diferentes oportunidades para os seus desenvolvimentos integrais. No entanto, o modo verticalizado como esse projeto educacional tem sido implementado, aliado com a precariedade como é desenvolvido, contribui ainda mais para as tensões no ambiente escolar, podendo agravar os problemas de violência nas escolas.

Mais uma vez percebe-se a violência vinculada ao caráter alienante e explorador na sociedade dividida por classes, que impede que 0 desenvolvimento humano ocorra dentro da máxima capacidade livre e universal de produção, materializada aqui nas políticas públicas, que, no entanto, são efetivadas em condições abaixo de suas pretensões.

Nesse sentido, verificou-se a partir do levantamento dos recursos humanos e estruturais da escola uma grande preocupação por parte dos gestores e servidores com relação a essa mudança no funcionamento da escola. Soares $(2013$, p. 6), ao pesquisar sobre essa temática concluiu que:

O citado programa não proporciona as condições materiais necessárias para desenvolver as atividades no contra turno escolar rumo à educação integral. As escolas em nada alteraram suas rotinas escolares; os resultados são catastróficos, corroborados pelos índices da Prova Brasil. $O$ 
Programa Mais Educação é um mecanismo de ajustamento dos indivíduos à ordem social vigente, em que fomenta um tipo de educação determinista, reproduzindo as contradições existentes numa sociedade estratificada em classes.

Para esse autor trata-se de uma ação verticalizada, que contribui ainda mais para o esvaziamento da função da escola como transmissora dos conteúdos sociais sistematicamente elaborados e historicamente acumulados pela humanidade, por meio da valorização de um conhecimento voltado unicamente aos interesses do sistema capitalista, ao mesmo tempo em que fortalece a reprodução das ideologias da sociedade de classes. Nas palavras de Soares (2013, p. 153) "[...] é um mecanismo de ajustamento dos indivíduos à ordem social vigente". Isso também ficou evidente na fala de um dos participantes da pesquisa, quando diz: "[...] se o ensino integral, no caso, funcionar como está no projeto, que tem que ter cursos técnicos. Contra turno tem que ter disciplinas diferenciadas. Sim, com certeza vai funcionar" (P1).

Para este professor a realização de aulas das disciplinas do núcleo comum nos dois períodos apenas sobrecarregou a escola, pois para ele os alunos deveriam aprender uma profissão, conforme enfatiza:

E outra coisa, se o filho no caso viesse no contra turno aprender uma profissão seria até bom, mas não, eles estão usando o horário integral somente pra estudar o convencional, história, geografia, matemática. Então houve uma sobrecarga das aulas convencionais no caso, não teve curso técnico, não teve algo assim, que chamasse a atenção deles pra cá. (P1)

Verifica-se que a fala do Pl se coaduna com a ideologia de uma sociedade classista quanto ao papel da escola na formação do aluno, fazendo com que a ênfase no ensino recaia na profissionalização do aluno, em detrimento do seu preparo para o ingresso nas universidades. Essa visão fomenta a separação do conhecimento técnico e científico, dando continuidade às contradições existentes numa sociedade dividida por classes. 
Percebeu-se que a escola pesquisada não foge dessa realidade, pois tanto a estrutura quanto a comunidade escolar não estavam preparadas para executar esse programa. É necessária a adequação da estrutura para poder atender a demanda, uma vez que na atualidade faltam espaços para atendimento aos alunos. Outro problema enfrentado pela escola ocasionado por essa medida foi o aumento da evasão escolar, conforme relatou um dos participantes: "[...] porque muitos pais não querem que o filho fique o dia todo na escola [...] Então muitos pais pegaram os alunos e tiraram e nós perdemos muitos alunos, alunos destaques nós perdemos." (P1).

S2, no entanto, levanta alguns pontos positivos quanto à educação integral como a oportunidade de alimentação dos alunos, conforme o relato: "Entram às sete da manhã, tomam o lanche, $11 \mathrm{~h} 30 \mathrm{~min}$ tem almoço. Os que querem almoçar, almoçam. Retornam às 13 h00min e 13h20min eles entram em sala de aula. A tarde tem um lanche para eles novamente, né?" e também o acompanhamento das atividades, quando diz: "Porque tinha muitos alunos que não faziam a tarefa, né? E agora com a escola integral, eles têm acompanhamento. Eles têm mais recursos. Foi muito bom". Ela deixa, no entanto, transparecer as dificuldades encontradas pela escola para sua implantação ao informar o horário de saída dos alunos, que ocorre às $15 \mathrm{~h} 20 \mathrm{~min}$, ao invés das $17 \mathrm{~h} 30 \mathrm{~min}$, pois a escola não dispõe de professores suficientes para atender o aumento da carga horária.

Nesse sentido, P1 reconhece que esse programa, implantado da forma como foi, não foi bom para escola. Segundo sua fala, "A escola ter tempo integral só jogou o índice da qualidade para baixo." O entrevistado continua: "[...] não, não pegou bem aqui". Para esse participante, isso fez com que toda a comunidade escolar sofresse um desgaste, conforme relata "[...] não só o desgaste destes [os alunos], da direção até a zeladoria o desgaste está geral". Um dos fatores que contribui para esse desgaste é a mudança constante nos horários que tem interferido no planejamento do professor. Conforme o mesmo participante: 
Antes quando não era horário integral você tinha um horário no início do ano que ia até o final, agora não, agora tá complicado, o horário muda cinco, seis, sete vezes. Eu moro muito longe, então esse ensino integral ele deixou meio desgastado. (P1)

Souza (2007) relata que a implantação de políticas públicas na educação tem sido marcada pelo autoritarismo, desconsiderando qualquer possibilidade de discussão e impedindo que o processo de objetivação e apropriação por parte dos professores ocorra de forma consciente, transformando-os em simples executores de medidas, o que gera sofrimento e prejudica o ensino.

Consequentemente, a escola passa a não conseguir executar adequadamente aquilo que foi pensado fora dela, tendo os professores dificuldade de internalizá-lo, produzindo práticas pedagógicas despersonalizadas e sem sentido, que acabam reverberando também de forma negativa no aluno que, da mesma forma que os outros integrantes da escola, são alienados desse processo. As consequências recaem também sobre o aluno, o qual não consegue atribuir sentido a essas medidas, acabando por sofrer conjuntamente.

Com isso, aquilo que deveria beneficiar a educação, torna-se mais um fator de agravamento das tensões que envolvem a escola, reduzindo-se cada vez mais a sua capacidade de suportar e gerir as situações de conflito. Baseando-se nas ideias de Charlot (2002), essa situação pode contribuir para a manifestação ou agravamento da violência na escola, pelo peso da violência social e simbólica que atinge a todos, como relatou Pl.

Embora seus integrantes não descrevam essas dimensões como violência, é possível perceber que eles conseguem identificar nessas ações impostas à escola um sofrimento, um desgaste, e, ainda que seja sútil e quase imperceptível, é tão danoso quanto à violência física, prescrita no código penal.

Verificamos no decorrer dessa análise que além das formas de violências física e verbal, praticadas tanto pelos alunos quanto pelos 
moradores do bairro. A existência de outras que perpassam o cotidiano do bairro e também da escola, deixando marcas indeléveis na comunidade, as quais estão escondidas nas politicas públicas que chegam à escola, nas relações hierarquizadas estabelecidas nela, na compreensão da violência como falta de normas e descumprimento das leis, nas desigualdades sociais, nas explorações das relações humanas e no capitalismo que cria as condições para as máximas possibilidades de desenvolvimento do gênero humano, mas que impõe barreiras que impedem a maioria da população de concretizarem essas possibilidades.

Conforme Abramovay e Ruas (2002), é mais fácil para o sistema educacional reconhecer os fatores externos como as principais causas da violência, do que aceitar que a própria escola contribui para manifestação da violência no seu interior por meio de suas práticas pedagógicas, fazendo com que esta negligencie sua responsabilidade diante do problema da violência escolar, impedindo a construção de alternativas verdadeiramente eficazes para seu enfrentamento.

Embora se compreenda a importância do estudo de Charlot (2002), ao propor uma distinção para as diferentes formas de manifestação do fenômeno em estudo no interior da escola, permitindo o avanço na compreensão dessa temática, observou-se que essa distinção da violência escolar reproduz, de certo modo, uma ideia de culpados/autores e vítimas. A forma como o autor apresenta as violências na, contra e da escola, estabelecendo uma relação apenas entre as duas últimas, cria uma relação de independência entre as formas de violência vindas de fora da instituição e as produzidas no seu interior. Nesse caso, para a primeira forma, continua o aluno ou o bairro como maior responsável, enquanto para a segunda forma a responsabilidade recai sobre a escola, prevalecendo as práticas pedagógicas como as maiores vilãs, sendo o professor o culpado.

Dessa maneira, consideramos que essa dicotomização da violência entre autores e vítimas, de fora e de dentro da instituição, não se aplica às considerações deste estudo. Ao longo de todo o processo de produção do 
conhecimento foi possivel perceber que tanto a violência vinda de fora quanto a violência produzida no interior da escola apresentam uma relação dialética entre seus diferentes tipos e causas, repercutindo na forma como os significados e sentidos são atribuídos pelos seus integrantes.

Compreendeu-se que a violência na escola é também uma violência contra e da escola, da mesma forma que estas últimas se relacionam com aquela. Para melhor expor essa ideia, utilizaremos como exemplo a forma como as políticas públicas chegam às escolas, sendo implantadas de modo autoritário. Esse é um tipo de violência na escola, uma vez que não se trata de casos isolados, mas se repete no cotidiano das instituições públicas. É também contra a escola, pois faz sofrer todos os seus integrantes e, por último, é da escola, quando praticada de forma alienada pelos representantes legais do sistema no interior da escola.

Portanto, reiterando as considerações iniciais, compreendendo o fenômeno da violência não como um somatório de fatos isolados, mas como processos que dialeticamente se relacionam, repercutindo a complexidade e ampliação do mesmo no contexto escolar, enquanto produto de relações sociais, cultural e historicamente estabelecidas pela humanidade.

\section{CONSIDERAÇÕES FINAIS}

Como já mencionado a compreensão restrita do conceito de violência impede que se percebam alguns tipos que escapam aos olhares conservadores, por não serem comtempladas pelas leis penais, uma vez que são praticadas de maneira sútil, realizadas no cotidiano social e muitas vezes aceitas como normais, mas que causam a destruição da humanidade do outro. A violência é um fenômeno multicausal, influenciado por diferentes fatores que se manifestam dialeticamente nas relações sociais, impossibilitando sua análise como uma questão isolada, dissociada do todo, mas como um componente social marcado hist oricamente por conflitos. 
Dessa forma, esta pesquisa buscou, através dos diferentes olhares daqueles que integram o cotidiano de uma escola de periferia urbana estigmatizada pela violência, analisar os significados e sentidos atribuídos a este fenômeno. Notou-se que a escola não pode ser vista como mera reprodutora da sociedade ou produto dos padrões sociais, mas ela também é produtora dos seus próprios padrões, como afirma Saviani (2008).

A análise de todo o material teórico-empírico produzido, apontou para a existência mais visível da violência, aos olhares dos participantes da pesquisa, predominando o sentido da violência como uma força vinda de fora das unidades de ensino, manifestada através da violência na escola e contra a escola. Desse modo, transfere somente ao aluno a responsabilidade pela violência, isentando a escola da violência produzida pela sua própria ação, o que é visto por Charlot (2002) como a violência da escola, a qual é invisível ou não percebida pelos entrevistados, fazendo com que o discurso culpabilizador se perpetve.

Contrário a esse entendimento, esse estudo mostrou que o professor age com violência quando passa a impor sua autoridade de forma autoritária, exercendo seu poder com arbitrariedade. Outra forma de violência invisível é aquela exercida pelas políticas educacionais impostas de modo verticalizado às escolas, pois ainda que tenham um sentido positivo para a educação, a forma como têm sido implantadas impede que de fato sejam. Corroborando essa compreensão, a pesquisa demonstrou que a maneira como os Programas de Educação Integral têm sido executados configura-se como uma violência da escola e também contra ela, fazendo sofrer tanto os professores quanto os alunos.

A violência percebida na escola está de acordo com o significado que tem chegado até ela, por meio de uma visão reducionista e culpabilizadora, que torna comum e naturaliza sua existência no cotidiano desses bairros. Isso contribui para a manutenção de outra violência contra essa comunidade: o preconceito e a discriminação que estigmatizam essa população por sua condição econômica e espacial. 
Ainda que não tenha ficado evidente que os alunos participantes deste estudo sejam aqueles considerados pela escola como "bons alunos", seus discursos, no entanto, apontam para um alinhamento ao discurso culpabilizador criador do estigma aluno "problema", o qual está presente entre os agentes escolares. Todavia, é importante destacar que os alunos entrevistados poderiam representar parte daqueles que se enquadram dentro dos padrões estabelecidos pela escola e que sem questioná-los incorporam de forma passiva, ou seja, aqueles normatizados. Uma questão que não foi discutida neste trabalho está relacionada aos alunos vistos com desconfiança pela escola, considerados os responsáveis pela violência escolar e definidos como alunos "problemas", por não se enquadrarem nos padrões ou por não aceitarem passivamente sua normatização. Certamente, caso o assunto fosse explorado, haveria outros olhares e novos questionamentos que ajudariam ampliar ainda mais a compreensão dessa temática, mas os limites deste trabalho impossibilitam o avanço nessa investigação, ficando para outras pesquisas essa tarefa.

\section{REFERÊNCIAS}

ABRAMOVAY, M.; CUNHA, A.L.; CALAF, P.P. Revelando tramas, descrobindo segredos: violência e convivência nas escolas. Brasília, DF: RITLA/SEEDF, 2009. p. 15-29.

ABRAMOVAY, M.; RUA, M. G. Violências nas escolas. Brasília: UNESCO, 2002.

AGUIAR, W. M. J.; SOARES, J. R.; MACHADO, V.C. Núcleo de significação: uma proposta histórica-dialética de apreensão das significações. Cadernos de Pesquisa. v. 45, n. 155, jan/mar. 2015. p. 56-75. Disponível em: $<$ http://www.scielo.br/pdf/cp/v45n155/1980-5314-cp-45-155-00056.pdf>. Acesso em: 04 jun. 2016.

ANSARA, S.; COSTA, G. P. A violência no ambiente escolar. In.: PAULA, F. V.; D'AUREA-TARDELI, D. (Orgs.). Violência na escola e da escola: desafios contemporâneos à Psicologia da Educação. São Paulo: Metodista, 2009. p. 89-102.

AQUINO, J. G. A desordem na relação professor aluno: indisciplina, moralidade e conhecimento. In: AQUINO, J. G. (org). Indisciplina na Escola: Alternativas Teóricas e Práticas. São Paulo: Summus, 1996. p. 39-55. 
BARROS, J. P. P.; PAULA, L. R. C. de; PASCUAL, J. G.; COLAÇO, V. de F. R. E.; XIMENES, V. M. O conceito de "sentido" em Vygotsky: considerações epistemológicas e suas implicações para a investigação psicológica. Psicologia \& Sociedade, Florianópolis, v. 21, n. 2, maio/ago. 2009. p. 174-181. Disponível em: http://dx.doi.org/10.1590/S0102-71822009000200004. Acessado em: 04 jun. 2016.

BOGDAN, R. C.; BIKLEN, S. K. Estudo de caso. In: BOGDAN, R. C.; BIKLEN, S. K. Investigação qualitativa em educação: uma introdução à teoria e aos métodos. Porto, Porto Editora, 1994. p. 89 - 97.

BRASIL. Port aria Normativa Interministerial n 17, de 24 de abril de 2007. Institui - Programa Mais Educação. Disponível em:< http://educacaointegral.mec.gov.br/images/pdf/port_17_12012010.pdf>. Acessado em 15 ago. 2016.

CHARLOT, B. A violência na escola: como os sociólogos franceses abordam essa quest ão. Sociologias. Porto Alegre, ano 4, nº 8, jul/dez 2002, p. 432-443.

COLLARES, C. A. L.; MOYSÉS, M. A. A. Preconceito no cotidiano escolar: ensino e medicalização. São Paulo: Cortez; Campinas: Unicamp/Faculdade de Educação/ Faculdade de Ciências Médicas, 1996.

CORRÊA, R. L. O espaço Urbano. $4^{a}$ edição. São Paulo: Ática, 2000.

D'AUREA-TARDELI, D. A prender a conviver: a violência no ambiente escolar. In.: PAULA, F. V.; D'AUREA-TARDELI, D. (Orgs.). Violência na escola e da escola:desafios contemporâneos à Psicologia da Educação. São Paulo: Metodista, 2009. p. 103-111.

DUARTE, N. A individualidade para-si: contribuições a uma teoria históricosocial da formação do indivíduo. $3^{a}$ ed. Campinas, SP. Autores Associados, 2013.

FACCI, M. G. D. Valorização ou esvaziamento do trabalho do professor? Um estudo críticocomparativo da teoria do professor reflexivo, do construtivismo e da psicologia Vigotskiana. Campinas: Autores Associados, 2004.

GOMES, R. A Análise de Dados em Pesquisa Qualitativa. In: MINAYO, M. C. de S. (Org.). Pesquisa Social: teoria, método e criatividade. Petrópolis, RJ: Vozes, 2002.

GUIMARÃES, A. M. Indisciplina e violência: a ambigüidade dos conflitos na escola. In: AQUINO, J. Q. (org). Indisciplina na Escola: Alternativas Teóricas e Práticas. São Paulo: Summus, 1996. p. 73-82.

REGO, T. C. R. A indisciplina e o processo educativo: uma análise na perspectiva vygotskiana. In: AQUINO, J. G. (org). Indisciplina na Escola: Alternativas Teóricas e Práticas. São Paulo: Summus, 1996. p. 83-101.

SA VIANI, D. Escola e democracia. Campinas - SP: Autores Associados, 2008. 
SILVA, N. R. Relações sociais para a superação da violência no cotidiano escolar e processos formativos de professores. 2006. $297 \mathrm{f}$. Tese (Doutorado em educação) - Pontifícia Universidade Católica de São Paulo, São Paulo, 2006 .

SOARES, D. P. A. Programa Mais Educação nas escolas estaduais de Porto Velho-RO: percursos para a educação integral. 2013. 182 f. Dissertação (Mestrado em Educação) - Fundação Universidade Federal de Rondônia, Porto Velho, 2013. Disponível em: <http://www.mestradoeducacao.unir.br/downloads/2265_dissertacao_domi ngos.pdf>. Acesso em: 17 jul. 2016.

SOUZA, B. de P. Funcionamentos escolares e a produção de fracasso escolar e sofrimento. In: SOUZA, B. de P. (Org.). Orientação à queixa escolar. São Paulo: Casa do Psicólogo, 2007. p. 241 -278.

SOUZA, E.C.S. Violência urbana e cultura escolar: estudo das percepções dos atores sociais em uma escola pública em Ananideua - PA. Rev. NUFEN, v. 3, n. 2011. $\quad 20 . \quad$ 116-137. Disponível em: http://pepsic.bvsalud.org/pdf/rnufen/v3n2/a07.pdf. Acessado em: 31 mar. 2015.

SPÓSITO, M. P. Um breve balanço da pesquisa sobre violência escolar no Brasil. In: Revista Educação e Pesquisa. São Paulo, v. 27, n.1, 2001. p. 87-103.

VIGOTSKI, L, S. A construção do pensamento e da linguagem. São Paulo: WMF Martins Fontes, 2009.

ZALUAR, A.; LEAL, M. C. Violência extra e intramuros. In: Revista Brasileira de Ciencias Sociais. v. 16, n. 45, 2001. p. 145-164.

Recebido em: Novembro de 2016 Aceito em: Maio de 2017 